\title{
5,6-EET Is Released upon Neuronal Activity and Induces Mechanical Pain Hypersensitivity via TRPA1 on Central Afferent Terminals
}

\author{
Marco Sisignano, ${ }^{1}$ Chul-Kyu Park, ${ }^{3}$ Carlo Angioni, ${ }^{1}$ Dong Dong Zhang, ${ }^{1}$ Christian von Hehn, ${ }^{2}$ Enrique J. Cobos, ${ }^{2}$ \\ Nader Ghasemlou, ${ }^{2}$ Zhen-Zhong Xu, ${ }^{3}$ Vigneswara Kumaran, ${ }^{5}$ Ruirui Lu, ${ }^{1}$ Andrew Grant, ${ }^{5}$ Michael J. M. Fischer, ${ }^{6}$ \\ Achim Schmidtko, ${ }^{1}$ Peter Reeh, ${ }^{4}$ Ru-Rong Ji, ${ }^{3}$ Clifford J. Woolf, ${ }^{2}$ Gerd Geisslinger, ${ }^{1}$ Klaus Scholich, ${ }^{1}$ \\ and Christian Brenneis ${ }^{1,2}$ \\ ${ }^{1}$ Institute of Clinical Pharmacology, Pharmazentrum Frankfurt/Center for Drug Research, Development and Safety (ZAFES), University Hospital, Goethe- \\ University, D-60590 Frankfurt am Main, Germany, ${ }^{2}$ F. M. Kirby Neurobiology Center, Children's Hospital Boston, and Department of Neurobiology, \\ Harvard Medical School, Boston, Massachusetts 02115, ${ }^{3}$ Department of Anesthesiology, Sensory Plasticity Laboratory, Pain Research Center, Brigham and \\ Women's Hospital and Harvard Medical School, Boston, Massachusetts 02115, ${ }^{4}$ Department of Physiology and Pathophysiology, Friedrich-Alexander- \\ University Erlangen-Nürnberg, D-91054, Erlangen, Germany, ${ }^{5}$ Wolfson Centre for Age Related Disease, King's College, London SE1 1UL, United Kingdom, \\ and ${ }^{6}$ Department of Pharmacology, University of Cambridge, Cambridge CB2 1PD, United Kingdom
}

Epoxyeicosatrienoic acids (EETs) are cytochrome P450-epoxygenase-derived metabolites of arachidonic acid that act as endogenous signaling molecules in multiple biological systems. Here we have investigated the specific contribution of 5,6-EET to transient receptor potential (TRP) channel activation in nociceptor neurons and its consequence for nociceptive processing. We found that, during capsaicin-induced nociception, 5,6-EET levels increased in dorsal root ganglia (DRGs) and the dorsal spinal cord, and 5,6-EET is released from activated sensory neurons in vitro. 5,6-EET potently induced a calcium flux (100 nM) in cultured DRG neurons that was completely abolished when TRPA1 was deleted or inhibited. In spinal cord slices, 5,6-EET dose dependently enhanced the frequency, but not the amplitude, of spontaneous EPSCs (sEPSCs) in lamina II neurons that also responded to mustard oil (allyl isothiocyanate), indicating a presynaptic action. Furthermore, 5,6-EET-induced enhancement of sEPSC frequency was abolished in TRPA1-null mice, suggesting that 5,6-EET presynaptically facilitated spinal cord synaptic transmission by TRPA1. Finally, in vivo intrathecal injection of 5,6-EET caused mechanical allodynia in wild-type but not TRPA1-null mice. We conclude that 5,6-EET is synthesized on the acute activation of nociceptors and can produce mechanical hypersensitivity via TRPA1 at central afferent terminals in the spinal cord.

\section{Introduction}

Transient receptor potential (TRP) channels are important transducers of external noxious and thermal stimuli on the peripheral terminals of sensory neurons (Patapoutian et al., 2009). Sensoryrelated TRP channels can be activated by heat (TRPV1-TRPV4), low $\mathrm{pH}$ (TRPV1), mechanical or osmotic stimulation (TRPA1, TRPV4), cool/cold temperatures (TRPM8, TRPA1), or pungent compounds with electrophilic properties that covalently bind to cysteine residues (TRPA1) (Clapham, 2003; Dhaka et al., 2006; Macpherson et al., 2007). The antinociceptive effects of TRPV1 and TRPA1 gene deletion, or their pharmacologic inhibition in various pain models, indicate the importance of TRP channel

Received November 20, 2011; revised February 16, 2012; accepted February 18, 2012.

This work was supported by the LOEWE Lipid Signaling Forschungszentrum Frankfurt (C.B.); German Research Association Grants BR 2923/1-1 (C.B.), SCH0817-2 (K.S.), and GE 695 (G.G.); National Institutes of Health Grants 2R37 NS039518-08 and 1P01NS072040 (C.J.W.); and Ministry of Science and Innovation/Fulbright program (E.J.C.).

Correspondence should be addressed to Christian Brenneis, Institute of Clinical Pharmacology, pharmazentrum frankfurt/Center for Drug Research, Development and Safety (ZAFES), University Hospital, Goethe-University, D-60590 Frankfurt am Main, Germany. E-mail: cbrenneis@gmx.de.

DOI:10.1523/JNEUROSCI.5793-11.2012

Copyright $\odot 2012$ the authors $\quad 0270-6474 / 12 / 326364-09 \$ 15.00 / 0$ activation and sensitization in diverse pain states (Caterina et al., 2000; Patapoutian et al., 2009).

Several lipid mediators have been identified as endogenous TRP agonists and are produced during tissue injury inflammation as a consequence of oxidative stress. The oxidized linoleic acid metabolites 9- and 13-hydroxyoctadecadienoic acid are formed in mouse and rat skin by exposure to noxious heat and contribute to the heat sensitivity of TRPV1 in rodents (Patwardhan et al. 2009, 2010). Oxidized eicosanoids such as the cyclopentones $\mathrm{PGA}_{2}$ and $15 \mathrm{~d}-\mathrm{PGJ}_{2}$ and the endogenous aldehyde 4-hydroxynonenal have been shown to produce acute pain via TRPA1 during inflammation (del Camino et al. 2010; Trevisani et al., 2007; Materazzi et al., 2008).

In a search for endogenous lipid mediators released by activity in nociceptors rather than by inflammation, we found elevated levels of 5,6-epoxyeicosatrienoic acid (5,6-EET) in dorsal root ganglia (DRGs) after capsaicin stimulation. 5,6-EET has been previously identified as an endogenous agonist of TRPV4, and its role in vascular endothelial cells has been analyzed in detail (Watanabe et al., 2003; Fleming and Busse, 2006). However, the functions of 5,6-EET in nociceptive processing are unknown. 
EETs are synthesized from the eicosanoid arachidonic acid (AA) by cytochrome P450-epoxygenase (CYP450). One of the four double bonds of AA is oxidized to an epoxide group leading to four regioisomers-5,6-EET, 8,9-EET, 11,12-EET, and 14,15EET - that can be released from cells to act as paracrine signaling mediators. Members of CYP450 with the highest epoxygenase activity toward AA belong to the CYP2C and CYP2J families (Spector and Norris, 2007). EET-synthesizing CYP450 enzymes are expressed in primary sensory neurons (Iliff et al., 2010). We found that deletion of soluble epoxide hydrolase, which metabolizes most EETs except 5,6-EET, attenuates inflammatory pain (Brenneis et al., 2011). We have now aimed to characterize the specific role of 5,6-EET in nociceptive processing.

We found that 5,6-EET, but not the other EETs, is increased in L4-L6 DRGs and the dorsal horn of the spinal cord during capsaicin-induced acute nociception, and selectively activates TRPA1 in a subpopulation of DRG neurons. 5,6-EET increases the frequency, but not the amplitude, of spontaneous EPSCs (sEPSCs) in spinal cord slices by TRPA1 activation. Finally, intrathecal injection of 5,6-EET induces a mechanical allodynia dependent on TRPA1. Our results identify 5,6-EET as an endogenous activator of TRPA1, the synthesis of which is induced by the acute activity of DRG neurons and facilitates spinal synaptic transmission causing mechanical allodynia.

\section{Materials and Methods}

Animals

All animal experiments were approved by the local Ethics Committees for Animal Research. For all behavioral experiments, we used only 6- to 12-week-old male C57BL/6 mice (Charles River or The Jackson Laboratory). TRPA1-deficient mice for behavioral studies were originally bred by Kwan et al. (2006) and were a generous gift from Dr. David Corey (Howard Hughes Medical Institute and Department of Neurobiology, Harvard Medical School, Boston, MA). To compare mechanical thresholds, we used age- and sex-matched littermates as control. For calciumimaging experiments, TRPA1-deficient and control strain (B6129PF2/J) mice were purchased from The Jackson Laboratory. TRPV4 wild-type and knock-out mice were a generous gift from Dr. Wolfgang Liedtke (Duke University, Durham, NC) and were bred in-house at King's College London (Grant et al., 2007).

\section{Plasmids}

Plasmids 3CK-human (h)TRPAl and (h)TRPAl were kindly provided by Dr. Sven Jordt (Department of Pharmacology, Yale University School of Medicine, New Haven, CT).

\section{Behavioral tests}

To test acute nociceptive behavior, the licking time was monitored for 45 min in 10 min intervals starting directly after injection. For the determination of mechanical allodynia, mice were kept in test cages on an elevated grid for at least $1.5 \mathrm{~h}$ to allow accommodation. Baseline measurements were performed using a Dynamic Plantar Aesthesiometer (Ugo Basile) to detect withdrawal latencies of the hindpaws after mechanical stimulation. The steel rod was pushed against the mid-plantar hindpaw with linear ascending force $(0-5 \mathrm{~g}$ over $10 \mathrm{~s}$, increasing $0.5 \mathrm{~g} / \mathrm{s})$ until a fast withdrawal response occurred. Slow movements of the paw were not counted. Paw withdrawal latencies were determined in seconds \pm 0.1 with a cutoff time of $20 \mathrm{~s}$. The noninjected and injected paws were measured alternately in intervals of 5-10 min. For determination of thermal thresholds, mice were kept in test cages on a warmed glass plate $\left(32^{\circ} \mathrm{C}\right)$ for at least $2 \mathrm{~h}$ on the first day to allow accommodation. Then the mid-plantar region of the paws was stimulated with a radiant heat device, consisting of a high-intensity projector lamp, until withdrawal occurred. The noninjected and injected paws were measured alternately in intervals of 5-10 min. For all behavioral tests, the investigator was blinded for treatment or genotype of the mice.

\section{Treatments}

For peripheral injections, $20 \mu \mathrm{l}$ of 5,6-EET ( $5 \mu \mathrm{M}$ ) (Cayman) was injected subcutaneously in the mid-plantar area of the hindpaw. Control animals received the corresponding volumes of acetonitrile [Sigma; $1.6 \%(\mathrm{v} / \mathrm{v})$ in PBS]. For intrathecal injections, the solvent of the 5,6-EET stock solution was changed to dimethylsulfoxide (DMSO). Five microliters of 5,6-EET $(10 \mu \mathrm{M})$ in $3.2 \% \mathrm{DMSO} /$ saline $(\mathrm{v} / \mathrm{v})$ were injected by direct lumbar puncture in awake, conscious mice. Briefly, a $10 \mu \mathrm{l}$ Hamilton syringe connected to a 30 gauge, 0.5 inch needle was inserted in a $70-80^{\circ}$ angle at the midline between the hip bones. After contact with the bone of the spinal column was sensed, the needle angle was reduced to $\sim 30^{\circ}$, and the needle was slipped in between the vertebrae. Drugs were injected immediately after a reflexive tail flick or an "S," shape indicating puncture of the dura mater.

\section{Primary DRG cultures}

Murine DRGs were dissected from spinal segments and directly transferred to ice-cold HBSS with $\mathrm{CaCl}_{2}$ and $\mathrm{MgCl}_{2}$ (Invitrogen). Next, isolated DRGs were incubated with collagenase/dispase $(500 \mathrm{U} / \mathrm{ml}$ collagenase; $2.5 \mathrm{U} / \mathrm{ml}$ dispase) in Neurobasal Medium containing L-glutamine $(2 \mathrm{~mm})$, penicillin $(100 \mathrm{U} / \mathrm{ml})$, streptomycin $(100 \mu \mathrm{g} / \mathrm{ml})$, $\mathrm{B}-27$, and gentamicin $(50 \mu \mathrm{g} / \mathrm{ml})$ (all from Invitrogen) at $37^{\circ} \mathrm{C}$ for 75 min. After removal of the collagenase/dispase-solution, cells were washed twice with Neurobasal Medium containing $10 \%$ fetal calf serum and were incubated for $10 \mathrm{~min}$ with $0.05 \%$ trypsin (Invitrogen). The washing steps were repeated, and the cells were mechanically dissociated with a $1 \mathrm{ml}$ Gilson pipette. Finally, the neurons were plated on poly-Llysine (Sigma)-coated glass coverslips and incubated with Neurobasal Medium containing L-glutamine $(2 \mathrm{mM})$, penicillin $(100 \mathrm{U} / \mathrm{ml})$, streptomycin $(100 \mu \mathrm{g} / \mathrm{ml}), \mathrm{B}-27$, and gentamicin $(50 \mu \mathrm{g} / \mathrm{ml})$ overnight until assessment by calcium imaging.

\section{Calcium-imaging experiments}

Calcium-imaging experiments were performed with two different setups. First, we used an Axioscope 2 upright microscope (Zeiss) with a $10 \times$ Achroplan water-immersion objective (Zeiss). The microscope was equipped with an Imago charge-coupled device (CCD) camera and a Polychrome IV monochromator (all TILL Photonics). Images were acquired every $2 \mathrm{~s}$ at both wavelengths (340 and $380 \mathrm{~nm}$ ) and were processed using the Tillvision software (Coste et al., 2008). Later, a Leica calcium-imaging setup, consisting of a Leica DMI 4000 b inverted microscope equipped with a DFC360 FX (CCD) camera, Fura-2 filters, and an N-Plan $10 \times / 0.25 \mathrm{Ph} 1$ objective (all from Leica), was used. Images were taken every $2 \mathrm{~s}$ and were processed with the LAS AF-software (Leica). For each experiment, we chose an area with large cell numbers and monitored 40-110 cells simultaneously. Calcium-imaging experiments were performed using DRG neurons $24-48 \mathrm{~h}$ after preparation. Cells were loaded with $5 \mu \mathrm{M}$ fura-2-AM-ester and 0.02\% Pluronic F-127 (both from Biotium) and were incubated for $30-60 \mathrm{~min}$ at $37^{\circ} \mathrm{C}$. Then the cells were washed with an external solution containing the following (in mM): $145 \mathrm{NaCl}, 1.25 \mathrm{CaCl}_{2}, 1 \mathrm{MgCl}_{2}, 5 \mathrm{KCl}, 10 \mathrm{D}$-glucose, and 10 HEPES, adjusted to $\mathrm{pH}$ 7.3. Baseline measurements were performed in external solution at a flow rate of $1-2 \mathrm{ml} / \mathrm{min}$. For EET stimulation, $10-500$ nм 5,6-EET (Cayman) was dissolved in external solution (directly before experiments) and applied by bath perfusion at room temperature. For control stimulations, the corresponding volume of acetonitrile (Sigma) was mixed in external solution and applied with the same flow rate. At the end of each measurement, cells were stimulated for $30 \mathrm{~s}$ with external solution, including an additional $36 \mathrm{~mm}$ $\mathrm{KCl}$ to identify viable neurons for the statistical evaluation. Calciumfree solutions were generated by the removal of $\mathrm{CaCl}_{2}$ and the addition of $2 \mathrm{~mm}$ EGTA, and osmotically controlled by increasing $\mathrm{NaCl}$ concentrations to $150 \mathrm{~mm}$. Stock solutions of HC-030031 (Sigma), AMG 9810 (Tocris Bioscience), and ruthenium red (RR) (Sigma) were diluted in external solution to their final concentrations $(20 \mu \mathrm{M}$ HC-030031, $1 \mu \mathrm{M}$ AMG 9810, $5 \mu \mathrm{M} R \mathrm{R})$. 
Determination of EETs by liquid chromatography-tandem mass spectrometry

Tissue sampling. At the indicated time points after intraplantar injection of $20 \mu \mathrm{l}$ of complete Freund's adjuvant (CFA), $25 \mu \mathrm{l}$ of capsaicin $(2 \mu \mathrm{g})$, or the corresponding volumes of PBS, tissue was dissected, weighted, and directly transferred to ethyl acetate (J.T. Baker), including $20 \mu \mathrm{l}$ of internal standards (5.6 EET-d11, 8.9 EET-d8, 11.12 EET-d8, and 14.15 EET$\mathrm{d} 8$, all with a concentration of $200 \mathrm{ng} / \mathrm{ml}$ in methanol, all from Cayman Chemical), and was stored at $-80^{\circ} \mathrm{C}$. The next day, tissue samples were homogenized in extraction solvents using a Retsch Mixer-Mill MM 200.

Sample extraction and standards. Stock solutions with $2500 \mathrm{ng} / \mathrm{ml}$ all analytes were prepared in methanol. Working standards were obtained by further dilution with a concentration range of $0.1-250 \mathrm{ng} / \mathrm{ml}$ for EETs. Sample extraction was performed with liquid-liquid extraction. Therefore, tissue or cell culture medium was extracted twice with $600 \mu \mathrm{l}$ of ethyl acetate. The combined organic phases were removed at a temperature of $45^{\circ} \mathrm{C}$ under a gentle stream of nitrogen. The residues were reconstituted with $50 \mu \mathrm{l}$ of methanol/water (50:50, v/v), centrifuged for $2 \mathrm{~min}$ at $10,000 \times g$, and transferred to glass vials (Macherey-Nagel) before injection into the liquid chromatography-tandem mass spectrometry (LC-MS/MS) system.

Instrumentation for measuring 5.6-EET, 8.9-EET, 11.12-EET, and 14.15-EET. The LC-MS/MS system consisted of an API 4000 triple quadrupole mass spectrometer (Applied Biosystems) equipped with a Turbo- $\mathrm{V}$ source operating in negative electrospray ionization mode, an Agilent 1100 binary HPLC pump and degasser, and an HTC Pal autosampler (Chromtech) fitted with a $25 \mu$ l LEAP syringe (Axel Semrau). High-purity nitrogen for the mass spectrometer was produced by a NGM 22-LC-MS nitrogen generator (cmc Instruments). For the chromatographic separation, a Gemini NX C18 column and precolumn were used $(150 \times 2 \mathrm{~mm}$ inner diameter, $5 \mu \mathrm{m}$ particle size, and $110 \AA$ pore size; Phenomenex). A linear gradient was used at a flow rate of $0.5 \mathrm{ml} / \mathrm{min}$ in mobile phase with a total run time of $17.5 \mathrm{~min}$. Mobile phase A was water/ammonia $(100: 0.05, \mathrm{v} / \mathrm{v})$, and mobile phase B was acetonitrile/ ammonia $(100: 0.05, \mathrm{v} / \mathrm{v})$. The gradient started from $85 \%$ in phase A to $10 \%$ within $12 \mathrm{~min}$. This was held for $1 \mathrm{~min}$ at $10 \%$ in phase A. Within 0.5 min, the mobile phase shifted back to $85 \%$ in phase A and was held for 3.5 min to equilibrate the column for the next sample. The injection volume of samples was $20 \mu \mathrm{l}$. Quantification was performed with Analyst software version 1.4.2 (Applied Biosystems) using the internal standard method (isotope-dilution mass spectrometry). Ratios of analyte peak area and internal standard area ( $y$-axis) were plotted against concentration ( $x$-axis), and calibration curves were calculated by least-squares regression with 1 /square concentration weighting.

\section{Spinal cord slice preparation and patch-clamp recordings}

As recently reported (Park et al., 2011), a portion of the lumbar spinal cord (L4-L5) was removed from mice (4-6 weeks old) under urethane anesthesia (1.5-2.0 g/kg, i.p.) and kept in preoxygenated ice-cold Krebs' solution. Transverse slices $(600 \mu \mathrm{m})$ were cut on a vibrating microslicer. The slices were perfused with Krebs' solution $(8-10 \mathrm{ml} / \mathrm{min})$ that was saturated with $95 \% \mathrm{O}_{2}$ and $5 \% \mathrm{CO}_{2}$ at $36 \pm 1{ }^{\circ} \mathrm{C}$ for at least $1-3 \mathrm{~h}$ before the experiment. The Krebs' solution contained the following (in $\mathrm{mm}$ ): $117 \mathrm{NaCl}, 3.6 \mathrm{KCl}, 2.5 \mathrm{CaCl}_{2}, 1.2 \mathrm{MgCl}_{2}, 1.2 \mathrm{NaH}_{2} \mathrm{PO}_{4}, 25 \mathrm{NaHCO}_{3}$, and 11 glucose.

The whole-cell patch-clamp recordings were made from lamina II neurons in voltage-clamp mode. Patch pipettes were fabricated from thin-walled, borosilicate, glass-capillary tubing ( $1.5 \mathrm{~mm}$ outer diameter; World Precision Instruments). After establishing the whole-cell configuration, neurons were held at the potential of $-70 \mathrm{mV}$ to record sEPSCs. The resistance of a typical patch pipette was 5-10 $\mathrm{M} \Omega$. The internal solution contained the following (in $\mathrm{mM}$ ): 135 potassium gluconate, 5 $\mathrm{KCl}, 0.5 \mathrm{CaCl}_{2}, 2 \mathrm{MgCl}_{2}, 5$ EGTA, 5 HEPES, and 5 ATP-Mg. Membrane currents were amplified with an Axopatch 200B amplifier (Molecular Devices) in voltage-clamp mode. Signals were filtered at $2 \mathrm{kHz}$ and digitized at $5 \mathrm{kHz}$. Data were stored with a personal computer using pCLAMP 10 software and analyzed with Mini Analysis (Synaptosoft).
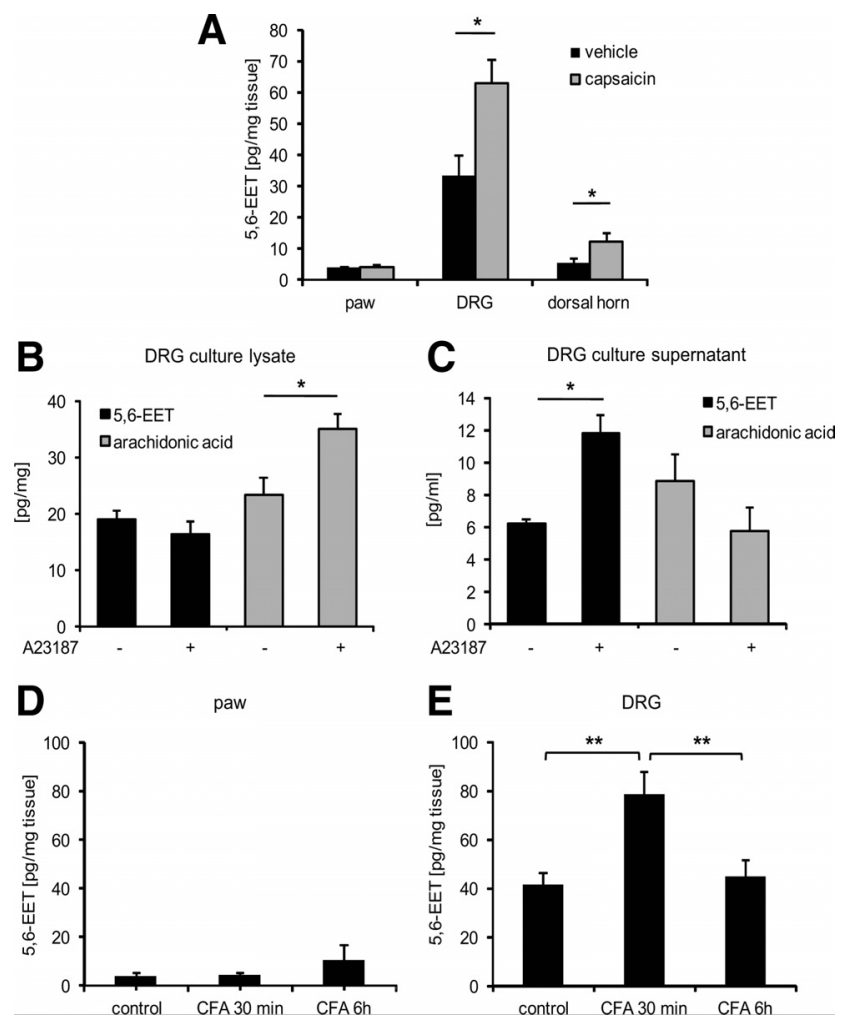

Figure 1. 5,6-EET concentrations in DRG tissue and release from sensory neurons upon activation. $A$, EET synthesis after nociceptive activation. 5,6-EET concentrations in the paw, L4 - L6 DRGs, and the dorsal horn of $\mathrm{L} 4-\mathrm{L} 6$ spinal cords were measured 30 min after intraplantar injection of capsaicin $(2 \mu \mathrm{g} / 25 \mu \mathrm{l})$ or vehicle. EET levels were determined from tissue extracts by LC-MS/MS. Shown is the average \pm SEM form tissues of 10 animals per group. $\boldsymbol{B}, \boldsymbol{C}$, Levels of $A A$ and 5,6-EET from cell lysates and supernatants of cultured DRG neurons. Neuron-enriched cultures from DRGs were incubated with A23187 (2 $\mu \mathrm{m})$ for $2 \mathrm{~h}$. Then EETs and AA were extracted from cell lysates $(\boldsymbol{B})$ or supernatants $(\boldsymbol{C})$ and quantified by LC-MS/MS analysis. Data shown represent the average \pm SEM from five culture dishes. $\boldsymbol{D}, \boldsymbol{E}$, Tissues from the plantar side of the paw $(\boldsymbol{D})$, and L4 -6DRGs $(\boldsymbol{E})$ were dissected 30 min or $6 \mathrm{~h}$ after intraplantar injection of 20 $\mu l$ of CFA or vehicle. EET levels were determined by LC-MS/MS. Shown is the average \pm SEM form tissues of six animals per group. ${ }^{*} p \leq 0.05,{ }^{* *} p \leq 0.01$; Student's $t$ test.

\section{Data analysis and statistics}

All data are presented as mean \pm SEM. To determine statistically significant differences in all behavioral experiments, ANOVA for repeated measures was used, followed by post hoc Bonferroni's correction using SigmaStat. For in vitro experiments comparing only two groups, Student's $t$ test was carried out. A $p$ value of $<0.05$ was considered statistically significant.

\section{Results}

Noxious stimulation increases 5,6-EET synthesis in DRGs

To analyze whether EET synthesis is regulated during nociception, we quantified EET levels in the paw, L4-L6 DRGs, and the dorsal horn of the spinal cord after an acute stimulus or during CFA-induced inflammation. TRPV1-expressing nociceptors were activated by intraplantar injection of capsaicin $(2 \mu \mathrm{g} / 25 \mu \mathrm{l})$. LC-MS/MS analysis of tissue extracts revealed that $30 \mathrm{~min}$ after capsaicin injection, 5,6-EET levels significantly increased in the DRGs and in the dorsal spinal cord but not in the paw (Fig. $1 A$ ). Notably, basal 5,6-EET levels were high in the DRGs but almost not detectable in the paw, suggesting that neuronal cells are a major source of 5,6-EET. Next, we investigated whether 5,6-EET is released from sensory neurons upon activation in vitro. Stimulation of primary neuronal cultures from DRGs of adult mice with the calcium ionophore A23187 ( $1 \mu \mathrm{M} ; 2 \mathrm{~h})$ caused a signif- 

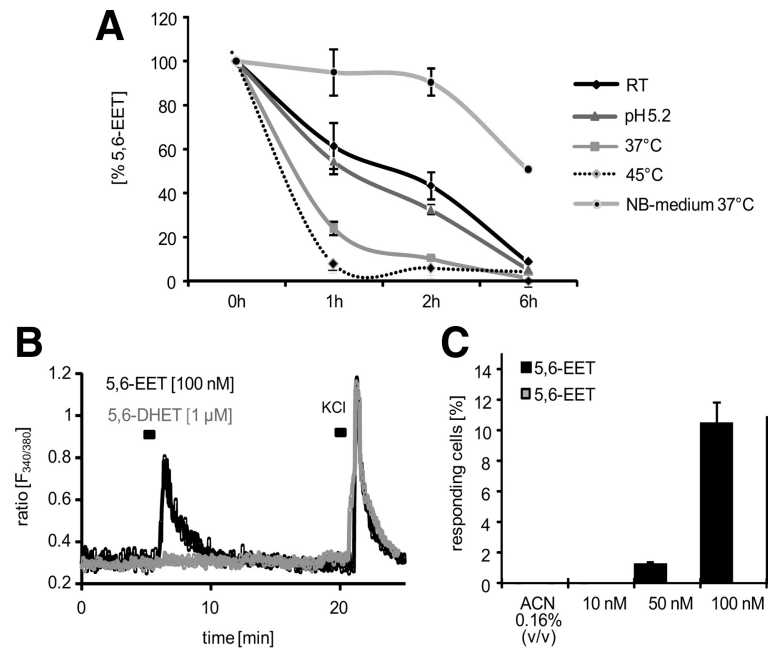

$C_{\text {u }}$ G 6 EET

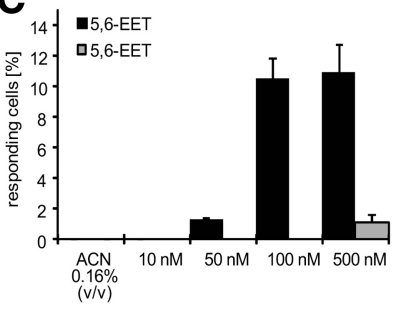

D

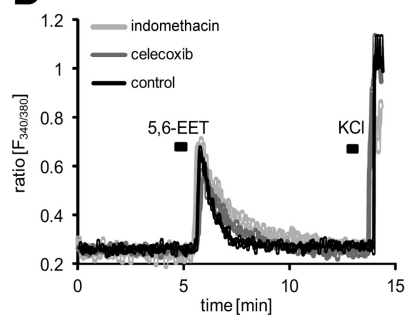

E

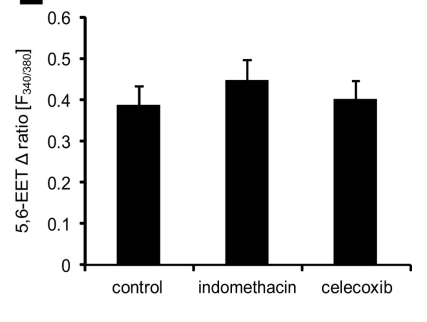

Figure 2. 5,6-EET induces calcium influx in sensory neurons. A, In vitro stability of 5,6-EET was tested under all buffer conditions ( $\mathrm{pH}$, temperature) used in this study. 5,6-EET $(1 \mu \mathrm{M})$ was dissolved in each buffer and was incubated for up to 6 h. 5,6-EET concentrations were measured from extracted buffers by LC-MS/MS. B, Stimulation of adult DRG neurons with 5,6-EET (100 nM, $10 \mathrm{~s})$, but not its metabolite 5,6-DHET (1 $\mu \mathrm{m}, 10 \mathrm{~s})$, induced a transient and reversible calcium flux. Neurons were identified by responses to $\mathrm{KCl}(40 \mathrm{~mm}, 10 \mathrm{~s})$. Shown is a representative trace. C, 5,6-EET dose dependently activates a maximal of $11 \%$ of DRG neurons. Cells were stimulated with different 5,6-EET concentrations or acetonitrile (ACN) as vehicle control ( $n=5-6$ experiments). D, Effects of COX inhibitors on 5,6-EET-mediated calcium flux in wild-type DRGs. Cultured DRG neurons were treated with $1 \mu \mathrm{m}$ indomethacin, $1 \mu \mathrm{m}$ celecoxib, or vehicle $(0.1 \%$ DMSO, v/v) $1 \mathrm{~h}$ before stimulation with 5,6-EET ( $250 \mathrm{~nm}$ ) and KCI ( $40 \mathrm{~mm}, 30$ s each). Shown are representative traces. $\boldsymbol{E}$, Statistical analysis of peak amplitudes from DRG neurons stimulated with 5,6-EET, as in $\boldsymbol{D}$ ( $n=6$ experiments each). NB, Neurobasal; RT, room temperature.

icant increase in 5,6-EET concentrations in the cell culture medium but not in cell lysates, suggesting that DRG neurons can synthesize and release 5,6-EET upon activation (Fig. $1 B, C$ ). Additionally, we determined AA levels in the DRG lysate and the supernatant after stimulation with A23187, and we observed elevated AA levels in the cells but not in the supernatant (Fig. 1C). The in vitro data indicated that upon activation, neurons produce AA, which is, in part, oxidized to 5,6-EET and can be released extracellularly. Although the DRG cultures consist primarily of neurons, they still contain small numbers of glia and fibroblasts, and a contribution of these cell types cannot be excluded.

To investigate the regulation of 5,6-EET synthesis in an inflammatory pain model, we measured 5,6-EET tissue levels after intraplantar injection of $20 \mu \mathrm{l}$ of CFA $30 \mathrm{~min}$ and $6 \mathrm{~h}$ after injection. At 30 min after CFA injection, an early point when animals show acute pain-like behavior (Ferreira et al., 2001), low levels of 5,6-EET with no significant difference to the vehicle-injected paws were detected (Fig. $1 D$ ). At $6 \mathrm{~h}$, when hyperalgesia and edematous tissue have developed in the paw (Gao et al., 2010), EET levels were still low. However, in DRGs from L4-L6 segments, 5,6-EET levels were markedly increased after $30 \mathrm{~min}$. Interestingly, this effect was not seen at the $6 \mathrm{~h}$ time point (Fig. $1 E$ ). Levels of other EET regioisomers (8,9-EET, 11,12-EET, and
A
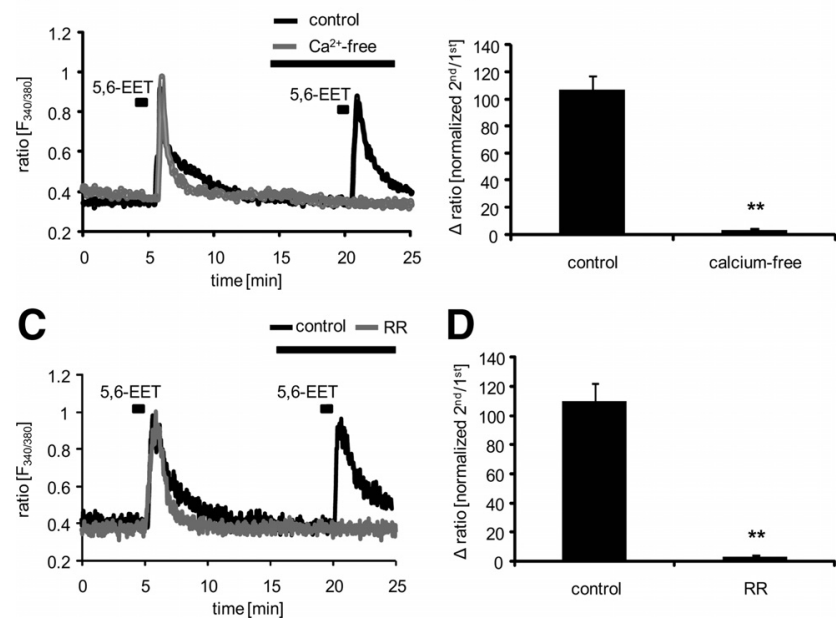

Figure 3. 5,6-EET induces calcium influx in DRG neurons by activation of TRP channels. $\boldsymbol{A}$, 5,6 -EET-induced calcium influx is blocked by $\mathrm{Ca}^{2+}$-free EGTA buffer. $\mathrm{Ca}^{2+}$-free EGTA buffer was washed in 5 min before a second 5,6-EET stimulation (100 nm, $10 \mathrm{~s}$ ). Shown are representative traces of control (black) and $\mathrm{Ca}^{2+}$-free treated DRG neurons (gray). $\boldsymbol{B}$, Average values of peak amplitudes normalized to the control (first 5,6-EET stimulation) peaks of traces from cells as stimulated in $\boldsymbol{A}$ ( $n=5-6$ experiments). C, 5,6-EET-induced calcium influx is blocked by RR. Five micrometers of RR were washed in for 5 min before DRG neurons were again stimulated with 5,6-EET (100 nM, $10 \mathrm{~s}$ ). Shown are representative traces of control (black) and RR (5 $\mu \mathrm{m}$; gray) treated DRG neurons. $\boldsymbol{D}$, Average values of peak amplitudes normalized to the control (first 5,6-EET stimulation) peaks of traces as in $C\left(n=6-7\right.$ experiments). ${ }^{* *} p<0.01$; Student's $t$ test.

14,15-EET) were not altered in any model and tissue (data not shown), thus indicating that acute nociceptive stimulation selectively induces the synthesis of 5,6-EET in sensory neurons during acute pain. We conclude that 5,6-EET production is triggered by neural activity rather than by the infiltration and activation of immune cells.

\section{5,6-EET induces a TRPA1-mediated calcium influx in DRG neurons}

To investigate whether 5,6-EET has direct effects on sensory neurons, we performed calcium-imaging experiments with neurons from DRGs of adult mice in vitro.

Given that 5,6-EET may be unstable because of degradation by auto-hydrolyzation (Nüsing et al., 2007), the relative stability of 5,6-EET in extracellular solution was tested in all buffers and under all temperature and $\mathrm{pH}$ conditions used in this study. There was no significant difference between the stability of 5,6-EET comparing the buffers (Fig. 2A). In contrast, temperature-related 5,6EET stability differed. However, at room temperature, $>40 \%$ of 5,6-EET remained after $2 \mathrm{~h}$ (Fig. $2 \mathrm{~A}$ ), indicating sufficient stability for short-term in vitro experiments.

In calcium-imaging experiments, we observed a fast and transient response to a $10 \mathrm{~s}$ stimulation with $100 \mathrm{~nm}$ 5,6-EET but not to its metabolite $1 \mu \mathrm{M}$ 5,6-dihydroxyeicosatrienoic acid (DHET) in a subset of neurons (Fig. $2 B$ ). Next, we determined the percentage of 5,6-EET-responding cells (in a concentration range of $10-500 \mathrm{~nm}$ ) among all neurons (40 mM KCl-responding cells) and found that $11 \%$ of the DRG neurons were activated by 100 nM 5,6-EET (Fig. 2C). Higher concentrations of 5,6 EET (up to $500 \mathrm{~nm}$ ) did not further increase the number of responding neurons. To investigate the contribution of putative cyclooxygenase (COX)-metabolites of 5,6-EET, we incubated DRG cultures with indomethacin $(1 \mu \mathrm{M})$, celecoxib $(1 \mu \mathrm{M})$, or vehicle $(0.1 \%$ DMSO, 
A
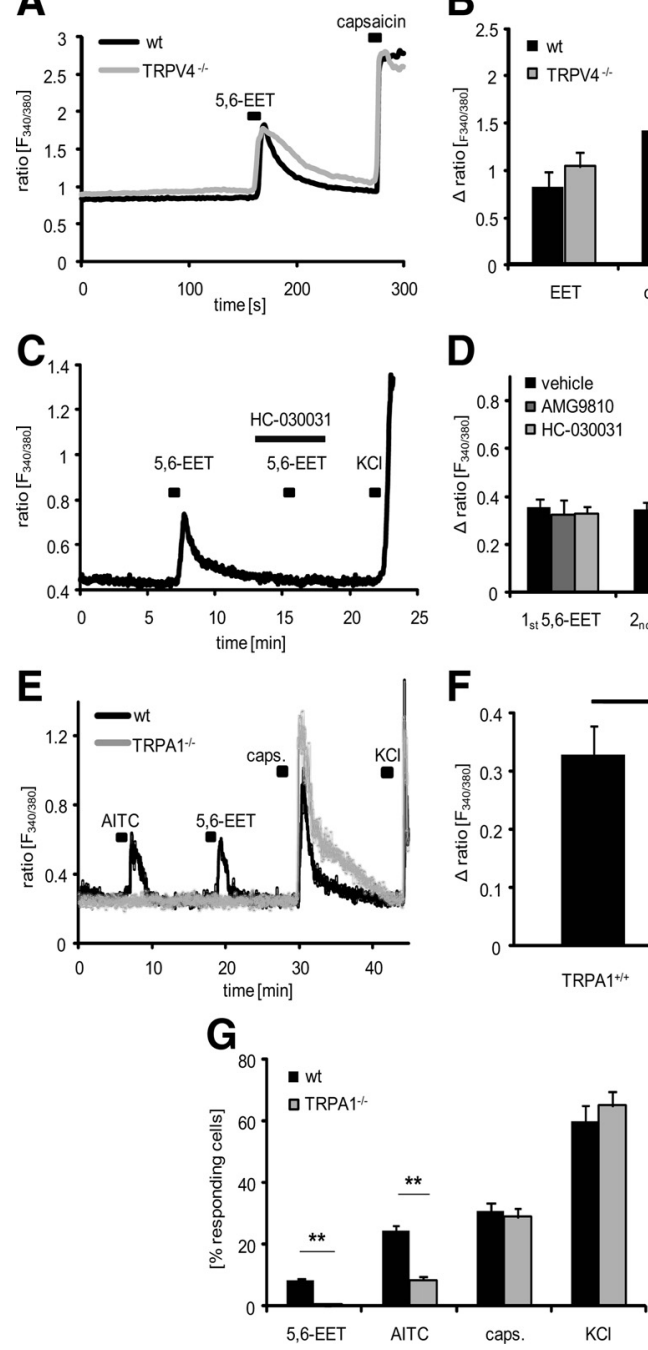

Figure 4. 5,6-EET-induced calcium influx in sensory neurons is mediated by TRPA1. A, 5,6EET-induced calcium influx does not depend on TRPV4. 5,6-EET ( $300 \mathrm{~nm}, 10$ s)-induced calcium fluxes in DRG neurons from wild-type and TRPV4 ${ }^{-1-}$ mice were compared. Shown is a representative trace. $\boldsymbol{B}$, Statistical analysis of neurons as shown in $\boldsymbol{A}(n=150-200$ cells). $\boldsymbol{C}$, Effect of the selective TRPA1-antagonist HC-030031 (20 $\mu \mathrm{M})$ on 5,6-EET (250 nM)-induced calcium flux. Shown is a representative trace. D, Statistical analysis of the effects of the TRPV1 (AMG9810, 1 $\mu \mathrm{M}$ ) and TRPA1 (HC-030031, $20 \mu \mathrm{m}$ ) antagonists on 5,6-EET-induced peak amplitudes ( $n=$ 5- 6 experiments). $E$, DRG neurons from TRPA1 ${ }^{-1-}$ mice (gray) respond less to AITC (100 $\mu \mathrm{M}$, $30 \mathrm{~s}$ ) and not to 5,6-EET ( $250 \mathrm{~nm}, 30 \mathrm{~s})$ but do respond similarly to capsaicin ( $250 \mathrm{~nm}, 30 \mathrm{~s})$ and $\mathrm{KCl}$ $(40 \mathrm{~mm}, 30 \mathrm{~s})$. Shown are representative traces. $\boldsymbol{F}$, Statistical analysis of the peak amplitudes from recordings of wild-type and TRPA1-deficient DRG neurons after 5,6-EET stimulation (250 $\mathrm{nM})$. Shown is the average \pm SEM from six to eight experiments. $G$, Percentage of responding cells stimulated as shown in $\boldsymbol{E}$ from wild-type and TRPA1-deficient DRG neurons. Shown is the average \pm SEM from six to eight experiments. ${ }^{* *} p<0.01$; Student's t test. caps., Capsaicin; wt, wild-type.

v/v) $1 \mathrm{~h}$ before stimulation with $250 \mathrm{~nm} 5,6$-EET and $40 \mathrm{~mm} \mathrm{KCl}$ (Fig. 2D). However, we could not detect any differences in the response amplitudes to 5,6-EET (Fig. 2E), suggesting that COX metabolites of 5,6-EET are not responsible for the observed effects.

To test whether the calcium flux arises because of entry of extracellular calcium or release from internal stores, we depleted calcium from the external solution with EGTA (2 mM). In $\mathrm{Ca}^{2+}$ free external solution, 5,6-EET-induced responses were abolished, indicating that calcium flux results from the extracellular solution (Fig. $3 A, B$ ). Next, we determined which calcium chan-
A



B

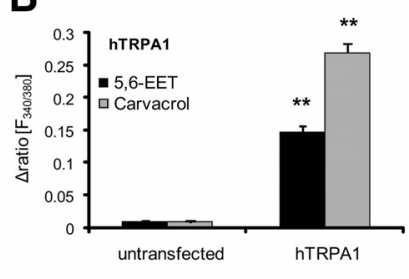

C

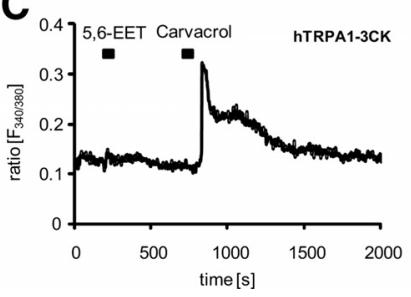

D

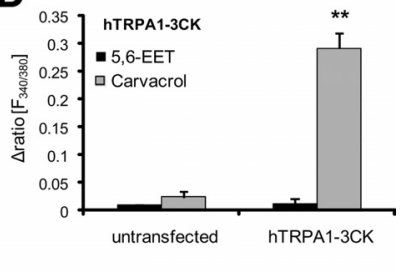

Figure 5. Role of regulatory cysteine residues for 5,6-EET-induced TRPA1 activation. $A$, HEK293 cells were transiently transfected with plasmids expressing (h)TRPA1 and stimulated with 5,6-EET $(250 \mathrm{~nm}, 30 \mathrm{~s})$ and carvacrol $(250 \mu \mathrm{m}, 30 \mathrm{~s})$. Shown is a representative trace. $\boldsymbol{B}$, Statistical analysis of the peak amplitudes of recordings from cells stimulated as in $\boldsymbol{A}$ ( $n=8$ experiments). C, HEK-293 cells were transiently transfected with plasmids expressing the (h)TRPA1 3CK mutant and stimulated as in $\boldsymbol{A}$. Shown is a representative trace. $\boldsymbol{D}$, Statistical analysis of the peak amplitudes of recordings from cells as in $C\left(n=9\right.$ experiments). ${ }^{* *} p \leq 0.01$; Student's $t$ test.

A

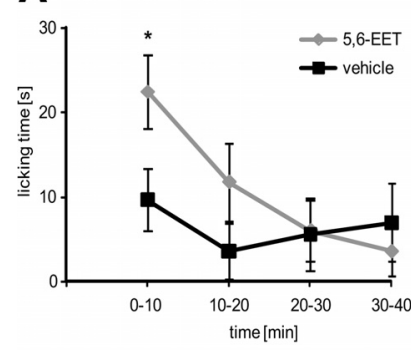

C

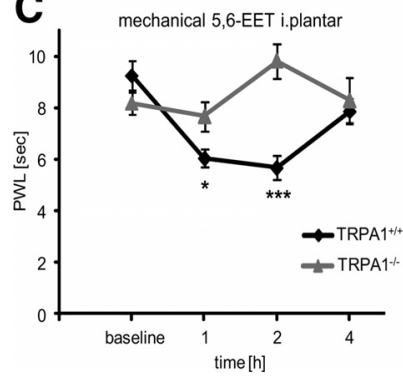

B mechanical 5,6-EET i.plantar

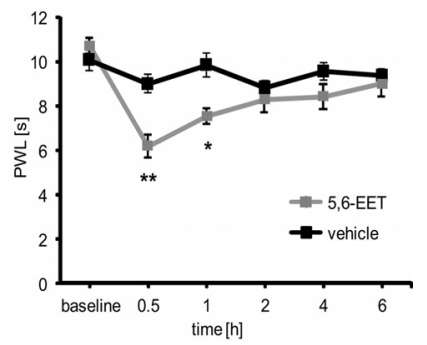

D

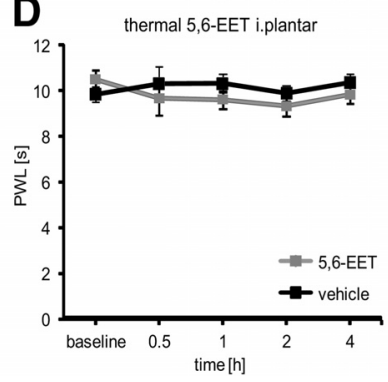

Figure 6. Peripheral TRPA1 activation by 5,6-EET causes acute pain and mechanical allodynia. A, Spontaneous pain induced by 5,6-EET. After intraplantar injection of $20 \mu \mathrm{l}$ of 5,6-EET $(5 \mu \mathrm{m}$ ) or vehicle (acetonitrile, $1.6 \%, \mathrm{v} / \mathrm{v}$ ), the licking time was monitored ( $n=8$ animals per group). $\boldsymbol{B}$, Mechanical allodynia after 5,6-EET injection. Dynamic plantar test after intraplantar injections of $20 \mu \mathrm{l}$ of 5,6-EET ( $5 \mu \mathrm{m}$ ) or vehicle ( $n=8-9$ animals per group). C, Comparison of mechanical allodynia in wild-type and TRPA1-deficient mice after intraplantar injection of 20 $\mu \mathrm{l}$ of 5,6-EET (5 $\mu \mathrm{m}$ ) or vehicle ( $n=8$ animals per group). D, 5,6-EET does not sensitize responses to a radiant heat stimulus. Hargreaves test after intraplantar injections of $20 \mu \mathrm{l}$ of 5,6-EET $(5 \mu \mathrm{M})$ or vehicle $\left(n=10\right.$ animals per group). ${ }^{*} p \leq 0.05,{ }^{* *} p \leq 0.01,{ }^{* * *} p \leq 0.001$; two-way repeated-measures ANOVA followed by Bonferroni's post-test. i. plantar, Intraplantar; PWL, paw withdrawal latency.

nels are involved in the 5,6-EET-induced calcium influx in the sensory neurons and tested the effect of the nonspecific TRP channel blocker RR. Five micrometers of RR completely abolished the 5,6-EET responses, suggesting that TRP channels may mediate the calcium influx (Fig. $3 C, D$ ). 
A

wt

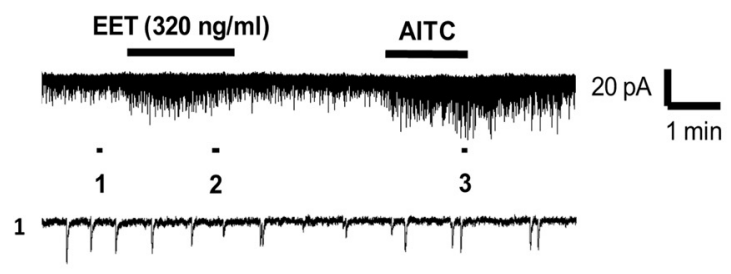

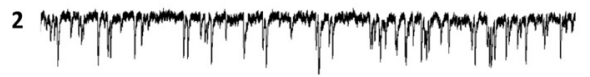

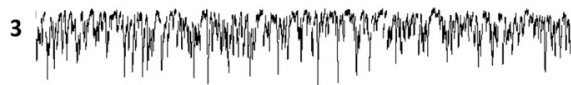

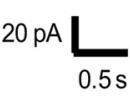

B
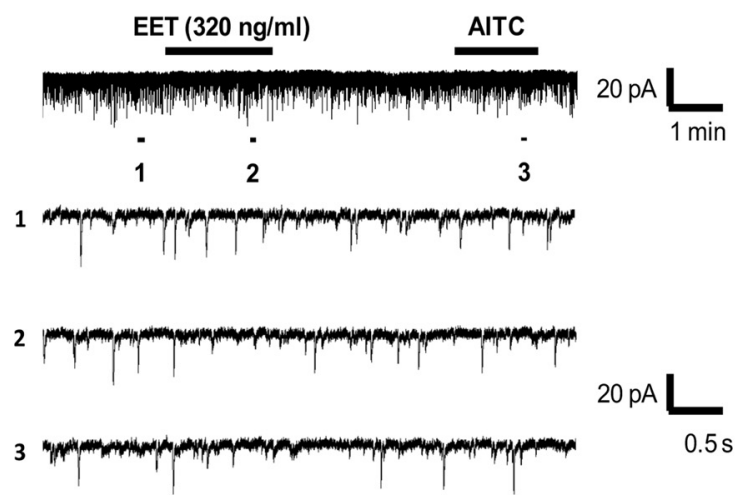

C
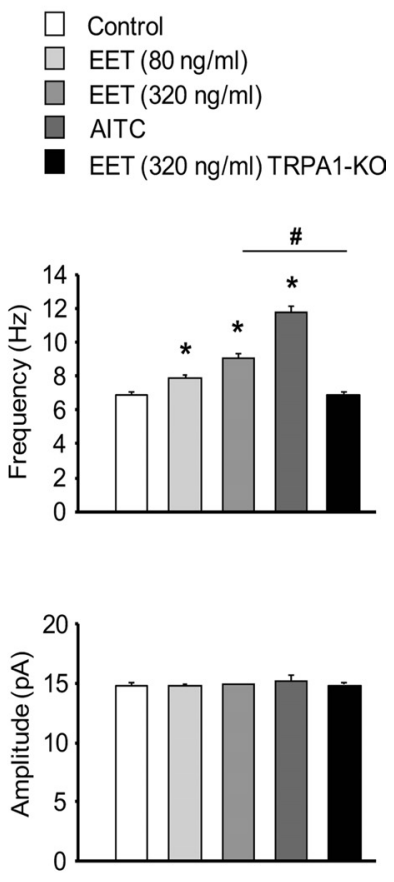

Figure 7. 5,6-EET enhances sEPSC frequency in lamina Il neurons of spinal cord slices through TRPA1.A, B, sEPSC traces recorded in spinal cord slices of wild-type $(\boldsymbol{A})$ and TRPA1-KO $(\boldsymbol{B})$ mice. 1, Trace before EET treatment; 2 , trace after EET treatment; 3 , trace after AITC treatment $(300 \mu \mathrm{m})$. Note that EET- and AITC-induced SEPSC increases are abolished in TRPA1-KO mice. C, sEPSC frequency (top) and amplitude (bottom). Note that EET and AITC increase only the frequency but not the amplitude of sEPSCs. ${ }^{*} p<$ 0.05 , compared with pretreatment baseline ( $n=5-10$ cells). K0, Knock-out; wt, wild-type.

To identify which TRP channels are involved, we used specific inhibitors of TRP channels and primary neurons from mice with targeted deletions. Because 5,6-EET activates TRPV4 in endothelial cells or when expressed heterologously (Watanabe et al., 2003; Vriens et al., 2005), we investigated DRG neurons from TRPV4 ${ }^{-1-}$ mice. Interestingly, there was no difference in the response to $300 \mathrm{nM}$ 5,6-EET between DRG neurons from wild-type or TRPV4 ${ }^{-1-}$ mice (Fig. $4 A, B$ ). Next, we determined whether the 5,6-EET response was blocked by the selective TRPV1 or TRPA1 antagonists AMG 9810 or HC-030031, respectively (Gavva et al., 2005; Eid et al., 2008). Although AMG 9810 had no effect, the selective TRPA1 antagonist HC-030031 completely blocked the 5,6-EET responses, leaving KClinduced calcium flux unaffected (Fig. 4C,D). Finally, we investigated 5,6 -EET responses in DRG neurons of TRPA1 ${ }^{-1-}$ mice. TRPA1deficient DRG neurons responded normally to capsaicin (250 nM, $30 \mathrm{~s}$ ) and $\mathrm{KCl}(40 \mathrm{~mm}, 30 \mathrm{~s}$ ) (Fig. 4E,G). However, 5,6-EET (250 $\mathrm{nM}, 30 \mathrm{~s}$ ) did not induce any calcium flux, and the number of allyl isothiocyanate (AITC)-responsive neurons was markedly reduced (100 $\mu \mathrm{M}, 30 \mathrm{~s})$ (Fig. 4F, G). The data suggest that 5,6-EET responders are TRPA1/TRPV1-positive DRG neurons and that the 5,6-EET-induced calcium influx is mediated by TRPA1.

5,6-EET-induced activation of TRPA1 requires intracellular cysteine residues

Most chemical irritants or endogenous molecules that activate TRPA1 are $\alpha, \beta$-unsaturated electrophilic aldehydes that regulate channel gating by covalent modification of cysteine residues located on the $\mathrm{N}$-terminal cytosolic domain (Macpherson et al., 2007). 5,6-EET also has electrophilic properties, carrying partially positive charges at the $5^{\prime}$ and $6^{\prime}$ carbons of its epoxide group. To analyze a putative interaction between 5,6EET or a 5,6-EET response factor and N-terminal regulatory cysteines of TRPA1, a previously characterized (h)TRPA1 variant with mutated interaction sites (C619, C639, C663, and K708; denoted 3CK) (Bessac et al., 2008) was expressed in HEK293 cells. Activation with $250 \mathrm{~nm}$ 5,6-EET and $250 \mu \mathrm{M}$ carvacrol, a nonreactive agonist of TRPA1, was compared with calcium imaging. Cells expressing wild-type TRPA1 responded to both with a robust and reversible calcium transient (Fig. $5 A, B$ ). In contrast, cells expressing the $3 \mathrm{CK}$ mutant did not show any calcium flux after the 5,6EET application, whereas carvacrolinduced responses were unchanged (Fig. $5 C, D)$. These results clearly suggest that 5,6EET or a possible intermediate factor induced by 5,6-EET activates TRPA1 in the same way as pungent electrophiles such as AITC through an interaction with intracellular cysteine residues.

Peripheral 5,6-EET injections produce acute pain and mechanical allodynia TRPA1 agonists directly induce and sensitize nociceptive behavior when injected into the paw (Bautista et al., 2006; McNamara et al., 2007). To test whether 5,6EET has a similar effect, we injected $5 \mu \mathrm{M}$ 5,6-EET into the plantar surface of a hindpaw and determined the acute nociceptive response in mice. 5,6-EET induced a significantly elevated acute licking response in the first $10 \mathrm{~min}$ after injection compared with vehicle control (1.6\% acetonitrile/PBS, v/v) (Fig. 6A). Then the effect of intraplantar 5,6-EET on mechanical threshold was assessed with a dynamic plantar aesthesiometer ( 0.5 until $6 \mathrm{~h}$ after injection). We found that $5 \mu \mathrm{M} 5,6$ EET but not its vehicle significantly reduced mechanical thresholds at 0.5 and $1 \mathrm{~h}$ (Fig. 6B), which implies mechanical allodynia. Interestingly, this effect could not be observed in TRPA1-deficient mice, thus indicating a role for TRPA1 in 5,6EET-mediated reduced mechanical thresholds (Fig. 6C). Moreover, no differences in heat-evoked responses in the radiant heat test were detected when comparing $5 \mu \mathrm{M}$ 5,6-EET or vehicleinjected groups (Fig. 6D). In conclusion, intraplantar administration of 5,6-EET in mice induces acute pain behavior and mechanical allodynia but not thermal hyperalgesia that is dependent on TRPA1. This effect indicates that 5,6-EET has the capacity to activate TRPA 1 at peripheral nerve endings of nociceptors in vivo.

5,6-EET increases the frequency of sEPSC in spinal cord slices through TRPA1

To determine whether 5,6-EET could enhance spinal cord synaptic transmission by TRPA1 activation, we performed patchclamp recordings in spinal cord slices. Superfusion of spinal cord 
slices with 5,6-EET elicited a dose-dependent increase in the frequency, but not the amplitude, of sEPSC (Fig. 7A-C) in lamina II neurons, suggesting a presynaptic mechanism, likely through glutamate release from primary afferent central terminals (Park et al., 2011). Notably, all the lamina II neurons that responded to 5,6-EET also showed a profound increase in sEPSC frequency after AITC perfusion $(300 \mu \mathrm{M})$, suggesting that 5,6-EET could act on TRPA1-expressing central terminals (Fig. 7A). Neither 5,6EET nor AITC increased the amplitude of sEPSC (Fig. 7A-C), arguing against a postsynaptic mechanism. Importantly, both 5,6-EET and AITC-induced sEPSC frequency increases were completely lost in spinal cord slices prepared from TRPA1-null mice (Fig. 7C), suggesting that TRPA1 is required for 5,6-EETevoked enhancement of sEPSC frequency.

\section{Intrathecal injection of 5,6-EET causes mechanical allodynia} through activation of TRPA1

To further investigate the role of 5,6-EET as a putative pain mediator in the spinal cord, we injected $5 \mu \mathrm{l}$ of $10 \mu \mathrm{M} 5,6$-EET intrathecally and determined its effects on mechanical pain thresholds. Immediately after intrathecal injection of 5,6-EET or vehicle, we did not observe any spontaneous nocifensive behavior (data not shown). However, 5,6-EET, but not vehicle, induced mechanical allodynia for up to $60 \mathrm{~min}$ after injection (Fig. $8 \mathrm{~A}$ ). To investigate the contribution of TRPA1, we compared mechanical thresholds after intrathecal injection of $10 \mu \mathrm{M}$ 5,6-EET between wild-type and TRPA1-deficient mice and found mechanical allodynia after intrathecal 5,6-EET injection in wildtype but not in TRPA1-deficient mice, indicating that the central pronociceptive effect of 5,6-EET is mediated by TRPA1 (Fig. 8 B). Additionally, we investigated whether heat hyperalgesia occurs after intrathecal injection of $10 \mu \mathrm{M} 5,6$-EET injection and could not observe any differences in thermal thresholds compared with the vehicle controls (Fig. 8C), indicating that 5,6-EET-induced TRPA1 activation in the spinal cord does not affect thermal thresholds.

\section{Discussion}

Activation of TRPA1, expressed in a subset of TRPV1-expressing nociceptor fibers, contributes to mechanical pain hypersensitivity during several inflammatory and neuropathic pain states (da Costa et al., 2010; Wei et al., 2010, 2011; Kwan et al., 2009). Interestingly, in addition to systemic administration, intrathecal delivery of TRPA1 blockers is sufficient to reduce pain hypersensitivity (e.g., capsaicin-induced secondary mechanical hypersensitivity), indicating that centrally produced endogenous TRPA1 activators must be involved. We have now identified the CYP450 metabolite 5,6-EET as a potent endogenous TRPA1 agonist, in addition to its previously described action on TRPV4 (Watanabe et al., 2003), and have shown that it acts centrally.

Most pungent chemicals or endogenous molecules target TRPA 1 by an electrophilic interaction on its intracellular cysteine residues. 5,6-EET also has electrophilic properties, carrying partially positive charges at the $5^{\prime}$ and $6^{\prime}$ carbons at the epoxide ring. A lipid-epoxide cysteine interaction has been described in various biological pathways, such as for leukotriene C4 (LTC4) biosynthesis, where LTA4 is converted to LTC4 by a glutathione transferase (Murphy and Gijón, 2007). Interaction between the epoxide carbons of LTA4 and the free electron pair of the cysteine sulfur leads to opening of the epoxide ring and promotes conversion of LTA4 to LTC4. By using a TRPA1 mutant that lacks the critical intracellular cysteine residues, we show that cysteine modification is critical for TRPAl activation by 5,6-EET.

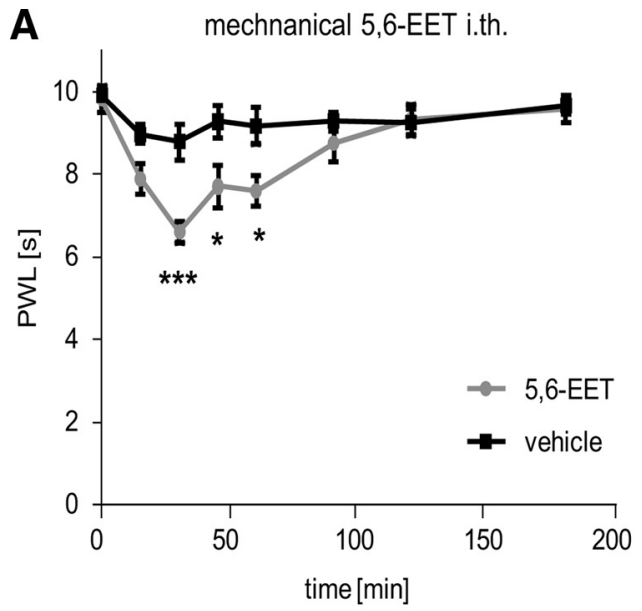

B mechnanical 5,6-EET i.th.
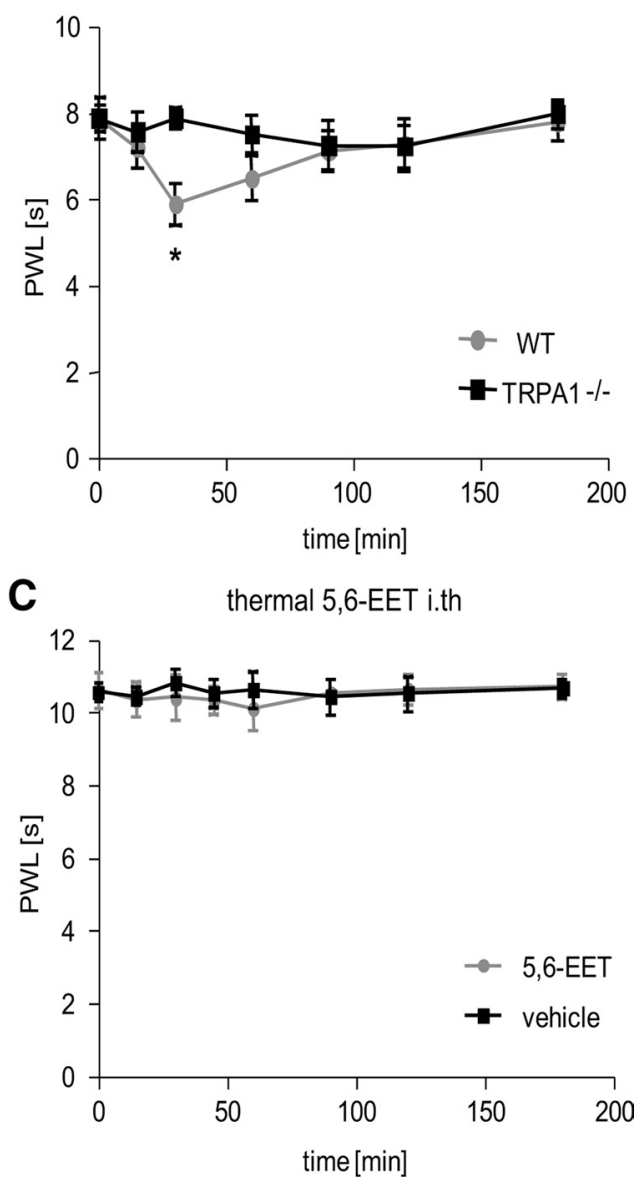

Figure 8. Intrathecal injections of 5,6-EET cause mechanical allodynia through the activation of TRPA1. A, 5,6-EET reduces mechanical thresholds when injected intrathecally. Five microliters of 5,6-EET (10 $\mu \mathrm{m}$ ) or vehicle (DMS0, 3.2\%, v/v) were injected intrathecally, followed by determination of the mechanical pain thresholds at time points $15,30,45,60,90,120$, and $180 \mathrm{~min}$ after injection using a dynamic plantar aesthesiometer. Shown is the average \pm SEM paw withdrawal latency from eight animals per group. $\boldsymbol{B}$, Comparison of mechanical thresholds in wild-type and TRPA1-deficient mice after intrathecal injections of $10 \mu \mathrm{l}$ of 5,6-EET (10 $\mu \mathrm{m})$ using a dynamic plantar aesthesiometer. Shown is the average \pm SEM from eight animals per group. C, Comparison of thermal thresholds in wild-type mice after intrathecal 5,6-EET injection $(10 \mu \mathrm{M})$ at the same time points shown in $\boldsymbol{A}$ using a Hargreaves apparatus. Shown is the average \pm SEM from six animals per group. ${ }^{*} p \leq 0.05,{ }^{* * *} p \leq 0.001$; two-way ANOVA followed by Bonferroni's post-test. i.th, Intrathecally; PWL, paw withdrawal latency; WT, wild-type. 
Whether 5,6-EET binds directly to TRPA1 or an intermediate factor is necessary requires further investigation.

Other endogenous molecules, such as 4-HNE and cyclopentones, also exhibit TRPA1-activating properties, but at considerably higher concentrations $(>30 \mu \mathrm{M})$ (Trevisani et al., 2007; Materazzi et al., 2008). Because of their generation by COX or reactive oxygen species, these lipid mediators are likely a consequence of invading immune cells and oxidative stress at the site of inflammation. We found that 5,6-EET is produced in the DRG and the dorsal spinal cord in response to nociceptive activation but not in inflamed tissues. Our data do support 5,6-EET as an inflammatory mediator, even though it can activate peripheral terminals, but its site of action appears to be on TRPA1 channels located in DRGs and on the central terminals of primary afferent fibers (da Costa et al., 2010; Wei et al. 2010), where the resultant calcium influx will increase transmitter release, and this synaptic facilitation or central sensitization will manifest as mechanical pain hypersensitivity. It is interesting that 5,6-EET is synthesized in the DRGs and in the dorsal spinal cord in response to nociceptor activity, and therefore the central activation of TRPA1 will be activity dependent. The comparison of EET concentrations in cell lysates and culture media indicates that after $\mathrm{PLA}_{2}$ activation, EETs are released extracellularly or are quickly hydrolyzed to their biologically inactive and more hydrophilic DHET metabolites (Brenneis et al., 2011). It is not clear yet whether TRPA1 activation by 5,6-EET represents an autocrine or a paracrine effect.

Nociceptive input induces spinal bradykinin production, which facilitates synaptic transmission and mediates capsaicin-induced secondary mechanical hyperalgesia (Wang et al., 2005). TRPA1deficient mice exhibit pronounced deficits in bradykinin-evoked pain hypersensitivity, and bradykinin induces EET release in several biological systems (Rastaldo et al., 2001; Bautista et al., 2006). We found a significant increase in EET synthesis in the dorsal spinal cord during acute pain when bradykinin is produced. Bradykinin might thereby induce secondary mechanical hyperalgesia by inducing EET release leading to TRPA1 activation on central afferent endings.

CYP2J isoforms, which exhibit strong epoxygenase activity toward AA and thus form EETs, are present in trigeminal sensory neurons and promote neuropeptide release (Iliff et al., 2010). Iliff et al. (2010) concluded that EETs are sensory neuron-derived activators that induce peripheral calcitonin gene-related peptide release causing vasodilatation, with a possible role in migraine. We argue that EETs may enhance transmitter release from nociceptor presynaptic terminals by the activation of TRPA1 to facilitate synaptic transmission and to produce mechanical allodynia. As a consequence, we found the frequency of spontaneous EPSPs (sEPSPs) increased in spinal cord slices. Given that the amplitudes of sEPSPs were not altered, we conclude that the 5,6-EET acts presynaptically to facilitate spinal transmission.

Mechanical hyperalgesia occurs during Taxol- and diabetesinduced neuropathy, in which an important contribution of endogenous TRPA1 or TRPV4 activation has been demonstrated (Quasthoff and Hartung, 2002; Alessandri-Haber et al., 2004; Wei et al., 2010). Interestingly, CYP2C enzyme activity, expression, or both are upregulated in these models (Gustafson et al., 2005; Elmi et al., 2008). Specific blocking of CYP450 signaling, therefore, may provide analgesia in chronic pain conditions and prevent painful side effects of cancer chemotherapy drugs.

Our data are compatible with the activity-dependent central synthesis of 5,6-EET and the activation of TRPA1 channels on the central terminals of nociceptors to facilitate synaptic transmission and to produce central sensitization. We suggest that 5,6-
EET is a centrally acting endogenous TRPA 1 activator with a role in producing mechanical pain hypersensitivity.

\section{References}

Alessandri-Haber N, Dina OA, Yeh JJ, Parada CA, Reichling DB, Levine JD (2004) Transient receptor potential vanilloid 4 is essential in chemotherapy-induced neuropathic pain in the rat. J Neurosci 24:4444-4452.

Bautista DM, Jordt SE, Nikai T, Tsuruda PR, Read AJ, Poblete J, Yamoah EN, Basbaum AI, Julius D (2006) TRPA1 mediates the inflammatory actions of environmental irritants and proalgesic agents. Cell 124:1269-1282.

Bessac BF, Sivula M, von Hehn CA, Escalera J, Cohn L, Jordt SE (2008) TRPA1 is a major oxidant sensor in murine airway sensory neurons. J Clin Invest 118:1899-1910.

Brenneis C, Sisignano M, Coste O, Altenrath K, Fischer MJ, Angioni C, Fleming I, Brandes RP, Reeh PW, Woolf CJ, Geisslinger G, Scholich K (2011) Soluble epoxide hydrolase limits mechanical hyperalgesia during inflammation. Mol Pain 7:78.

Caterina MJ, Leffler A, Malmberg AB, Martin WJ, Trafton J, Petersen-Zeitz KR, Koltzenburg M, Basbaum AI, Julius D (2000) Impaired nociception and pain sensation in mice lacking the capsaicin receptor. Science 288:306-313.

Clapham DE (2003) TRP channels as cellular sensors. Nature 426:517-524.

Coste O, Brenneis C, Linke B, Pierre S, Maeurer C, Becker W, Schmidt H, Gao W, Geisslinger G, Scholich K (2008) Sphingosine 1-phosphate modulates spinal nociceptive processing. J Biol Chem 283:32442-32451.

da Costa DS, Meotti FC, Andrade EL, Leal PC, Motta EM, Calixto JB (2010) The involvement of the transient receptor potential A1 (TRPA1) in the maintenance of mechanical and cold hyperalgesia in persistent inflammation. Pain 148:431-437.

del Camino D, Murphy S, Heiry M, Barrett LB, Earley TJ, Cook CA, Petrus MJ, Zhao M, D’Amours M, Deering N, Brenner GJ, Costigan M, Hayward NJ, Chong JA, Fanger CM, Woolf CJ, Patapoutian A, Moran MM (2010) TRPA1 contributes to cold hypersensitivity. J Neurosci 30:15165-15174.

Dhaka A, Viswanath V, Patapoutian A (2006) TRP ion channels and temperature sensation. Annu Rev Neurosci 29:135-161.

Eid SR, Crown ED, Moore EL, Liang HA, Choong KC, Dima S, Henze DA, Kane SA, Urban MO (2008) HC-030031, a TRPA1 selective antagonist, attenuates inflammatory- and neuropathy-induced mechanical hypersensitivity. Mol Pain 4:48.

Elmi S, Sallam NA, Rahman MM, Teng X, Hunter AL, Moien-Afshari F, Khazaei M, Granville DJ, Laher I (2008) Sulfaphenazole treatment restores endothelium-dependent vasodilation in diabetic mice. Vascul Pharmacol 48:1-8.

Ferreira J, Campos MM, Pesquero JB, Araújo RC, Bader M, Calixto JB (2001) Evidence for the participation of kinins in Freund's adjuvant-induced inflammatory and nociceptive responses in kinin B1 and B2 receptor knockout mice. Neuropharmacology 41:1006-1012.

Fleming I, Busse R (2006) Endothelium-derived epoxyeicosatrienoic acids and vascular function. Hypertension 47:629-633.

Gao YJ, Xu ZZ, Liu YC, Wen YR, Decosterd I, Ji RR (2010) The c-Jun $\mathrm{N}$-terminal kinase 1 (JNK1) in spinal astrocytes is required for the maintenance of bilateral mechanical allodynia under a persistent inflammatory pain condition. Pain 148:309-319.

Gavva NR, Tamir R, Qu Y, Klionsky L, Zhang TJ, Immke D, Wang J, Zhu D, Vanderah TW, Porreca F, Doherty EM, Norman MH, Wild KD, Bannon AW, Louis JC, Treanor JJ (2005) AMG 9810 [(E)-3-(4-t-butylphenyl)$N$-(2,3-dihydrobenzo[b][1,4] dioxin-6-yl)acrylamide], a novel vanilloid receptor 1 (TRPV1) antagonist with antihyperalgesic properties. J Pharmacol Exp Ther 313:474-484.

Grant A, Amadesi S, Bunnett NW (2007) Protease-activated receptors: mechanisms by which proteases sensitize TRPV channels to induce neurogenic inflammation and pain. In: Frontiers in neuroscience: TRP ion channel function in sensory transduction and cellular signaling cascades, Chap 31 (Liedtke WB, Heller S, eds). Boca Raton, FL: CRC.

Gustafson DL, Long ME, Bradshaw EL, Merz AL, Kerzic PJ (2005) P450 induction alters paclitaxel pharmacokinetics and tissue distribution with multiple dosing. Cancer Chemother Pharmacol 56:248-254.

Iliff JJ, Fairbanks SL, Balkowiec A, Alkayed NJ (2010) Epoxyeicosatrienoic acids are endogenous regulators of vasoactive neuropeptide release from trigeminal ganglion neurons. J Neurochem 115:1530-1542.

Kwan KY, Allchorne AJ, Vollrath MA, Christensen AP, Zhang DS, Woolf CJ, 
Corey DP (2006) TRPAl contributes to cold, mechanical, and chemical nociception but is not essential for hair-cell transduction. Neuron 50:277-289.

Kwan KY, Glazer JM, Corey DP, Rice FL, Stucky CL (2009) TRPA1 modulates mechanotransduction in cutaneous sensory neurons. J Neurosci 29:4808-4819.

Macpherson LJ, Dubin AE, Evans MJ, Marr F, Schultz PG, Cravatt BF, Patapoutian A (2007) Noxious compounds activate TRPA1 ion channels through covalent modification of cysteines. Nature 445:541-545.

Materazzi S, Nassini R, Andrè E, Campi B, Amadesi S, Trevisani M, Bunnett NW, Patacchini R, Geppetti P (2008) Cox-dependent fatty acid metabolites cause pain through activation of the irritant receptor TRPA1. Proc Natl Acad Sci U S A 105:12045-12050.

McNamara CR, Mandel-Brehm J, Bautista DM, Siemens J, Deranian KL, Zhao M, Hayward NJ, Chong JA, Julius D, Moran MM, Fanger CM (2007) TRPA1 mediates formalin-induced pain. Proc Natl Acad Sci U S A 104:13525-13530.

Murphy RC, Gijón MA (2007) Biosynthesis and metabolism of leukotrienes. Biochem J 405:379-395.

Nüsing RM, Schweer H, Fleming I, Zeldin DC, Wegmann M (2007) Epoxyeicosatrienoic acids affect electrolyte transport in renal tubular epithelial cells: dependence on cyclooxygenase and cell polarity. Am J Physiol Renal Physiol 293:F288-F298.

Park CK, Xu ZZ, Liu T, Lü N, Serhan CN, Ji RR (2011) Resolvin d2 is a potent endogenous inhibitor for transient receptor potential subtype v1/ a1, inflammatory pain, and spinal cord synaptic plasticity in mice: distinct roles of resolvin d1, d2, and e1. J Neurosci 31:18433-18438.

Patapoutian A, Tate S, Woolf CJ (2009) Transient receptor potential channels: targeting pain at the source. Nat Rev Drug Discov 8:55-68.

Patwardhan AM, Scotland PE, Akopian AN, Hargreaves KM (2009) Activation of TRPV1 in the spinal cord by oxidized linoleic acid metabolites contributes to inflammatory hyperalgesia. Proc Natl Acad Sci U S A 106:18820-18824.

Patwardhan AM, Akopian AN, Ruparel NB, Diogenes A, Weintraub ST, Uhlson C, Murphy RC, Hargreaves KM (2010) Heat generates oxidized li- noleic acid metabolites that activate TRPV1 and produce pain in rodents. J Clin Invest 120:1617-1626.

Quasthoff S, Hartung HP (2002) Chemotherapy-induced peripheral neuropathy. J Neurol 249:9-17.

Rastaldo R, Paolocci N, Chiribiri A, Penna C, Gattullo D, Pagliaro P (2001) Cytochrome P-450 metabolite of arachidonic acid mediates bradykinininduced negative inotropic effect. Am J Physiol Heart Circ Physiol 280:H2823-H2832.

Spector AA, Norris AW (2007) Action of epoxyeicosatrienoic acids on cellular function. Am J Physiol Cell Physiol 292:C996-C1012.

Trevisani M, Siemens J, Materazzi S, Bautista DM, Nassini R, Campi B, Imamachi N, Andrè E, Patacchini R, Cottrell GS, Gatti R, Basbaum AI, Bunnett NW, Julius D, Geppetti P (2007) 4-Hydroxynonenal, an endogenous aldehyde, causes pain and neurogenic inflammation through activation of the irritant receptor TRPAl. Proc Natl Acad Sci U S A 104:13519-13524.

Vriens J, Owsianik G, Fisslthaler B, Suzuki M, Janssens A, Voets T, Morisseau C, Hammock BD, Fleming I, Busse R, Nilius B (2005) Modulation of the $\mathrm{Ca} 2$ permeable cation channel TRPV4 by cytochrome $\mathrm{P} 450$ epoxygenases in vascular endothelium. Circ Res 97:908-915.

Wang H, Kohno T, Amaya F, Brenner GJ, Ito N, Allchorne A, Ji RR, Woolf CJ (2005) Bradykinin produces pain hypersensitivity by potentiating spinal cord glutamatergic synaptic transmission. J Neurosci 25:7986-7992.

Watanabe H, Vriens J, Prenen J, Droogmans G, Voets T, Nilius B (2003) Anandamide and arachidonic acid use epoxyeicosatrienoic acids to activate TRPV4 channels. Nature 424:434-438.

Wei H, Chapman H, Saarnilehto M, Kuokkanen K, Koivisto A, Pertovaara A (2010) Roles of cutaneous versus spinal TRPAl channels in mechanical hypersensitivity in the diabetic or mustard oil-treated non-diabetic rat. Neuropharmacology 58:578-584.

Wei H, Koivisto A, Saarnilehto M, Chapman H, Kuokkanen K, Hao B, Huang JL, Wang YX, Pertovaara A (2011) Spinal transient receptor potential ankyrin 1 channel contributes to central pain hypersensitivity in various pathophysiological conditions in the rat. Pain 152:582-591. 